\title{
Phonological processing in reading: data from alexia
}

\author{
J. DÉROUESNÉ A N M. F. BEA U VOIS \\ From Laboratoire de Neuropsychologie INSERM U.84, Hôpital de la Salpêtrière, Paris, France
}

SUMMARY The reading of four subjects suffering from a phonological reading impairment as a result of a cerebral lesion was tested. A double dissociation observed in their results is strong evidence for the existence of two functionally independent kinds of phonological processing in reading - a graphemic and a phonetic one.

A difference in reading performance when stimuli do or do not have meaning has often been reported in some varieties of alexia (Alajouanine et al., 1960; Benson et al., 1971; Dubois-Charlier, 1972; Gardner and Zurif, 1975; Kremin and Dubois-Charlier, 1976; Benson, 1977). Stimuli with little or no meaning (letters, non-words, and grammatical words) are misread, while meaningful stimuli, such as nouns, are read better. Several studies have already been undertaken of the variables affecting the reading of meaningful stimuli (Marshall and Newcombe, 1966, 1973; Andreewsky and Séron, 1975; Gardner and Zurif, 1975; Shallice and Warrington, 1975; Kremin and Dubois-Charlier, 1976; Saffran et al, 1976), but experimental studies bearing especially on the reading of meaningless stimuli in cases of alexia are still rare. They deal with the reading either of letters (Shallice and Warrington, 1977) or of nonwords. Patterson and Marcel (1977) and Saffran and Marin (1977) provided some evidence for the existence of a phonological impairment which made impossible the reading of non-words. The existence of this impairment has been demonstrated experimentally in one particular case of alexia which has been called phonological alexia (Beauvois and Dérouesné, 1979). In the latter study we have established a close connection between the different kinds of written stimulus and the process used in reading. While meaningful stimuli can be read by means of the non-phonological or lexical reading process, meaningless stimuli have to be read by means of phonological reading process. Furthermore, this study showed that some defects in the phonological process are

Address for correspondence and reprint requests: Dr J. Dérouesné, Laboratoire de Neuropsychologie INSERM U.84, Hôpital de la Salpêtrière, 47 Bd de l'Hôpital, 75634 Paris Cedex 13, France. Accepted 12 May 1979 related neither to a verbalisation impairment nor to impairment of visual identification, but to an impairment of the intermediate phonological state (grapheme-phoneme correspondence). The present study concerns the phonological reading process. Its aim is to distinguish two kinds of phonological processing involved in grapheme-phoneme correspondence one which has been called the "graphemic processing" because it concerns the processing of graphemes, and another which has been called the "phonemic processing" because it concerns the production of the sound of phonemes.

The graphemic processing is assumed to bring into play the use of phonological rules peculiar to written language which condition its translation into sounds. For example, in non-words, some letters always correspond to the same phoneme (for example in French, the letter $\mathrm{K}$ always corresponds to the phoneme $/ \mathrm{k} /$ ), whereas other letters correspond to different phonemes according to the vowel which precedes or follows them (in French G corresponds to the phonemes / $/$ / or $/ g /$ according to whether it is followed by the letter $\mathrm{E}$ or $\mathrm{A}$ ). In some cases, each letter corresponds to a phoneme; in others several letters have to be processed together to form a phoneme. For ¿xample, in the non-word Ko, $\mathrm{K}$ and o both correspond to a phoneme, whereas in the non-word KEAU, the sequence of three letters E, A, U corresponds to a single phoneme $/ \mathrm{o} /$. Taking into account the preceding or the following letter(s) before translating a particular letter into a phoneme depends on the graphemic processing. This graphemic processing which is phonological must be distinguished clearly from other kinds of processing which are also necessary for the translation into sounds of certain grapheme sequences, particularly semantic and syntactic processing-for example, the fact that, in French, 
the three letters of the written word EST can correspond to one phoneme $(/ \varepsilon /)$ or to three phonemes (/ Est /) according to whether the word is an auxiliary or a noun, does not depend on this phonological graphemic processing, but on semantic and syntactic processing.

The phonemic processing is assumed to bring into play the use of rules peculiar to the production of sounds from written language. It leads to the utterance of syllables or clusters of syllables through the evocation of sounds of each phoneme (or clusters of phonemes). This phonemic processing involved in the phonological reading process must be distinguished clearly from three other kinds of processing. Firstly, because it is phonological, it is completely different from the phonetic processing. For example, the fact that $B$ is pronounced $b$ in the non-word BLA and $p$ in the non-word BTA does not depend on phonemic rules but on phonetic constraints (it is not possible to pronounce $b$ and $t$ consecutively). Secondly, because it is phonemic, the unit involved is the phoneme. This means that this phonemic processing is completely different from the processing leading to the production of the sounds of phonemes included in a word. In the latter case, it is probably not a question of the evocation of the sound of each phoneme but of the evocation of the global sound form of the word. Thirdly, because reading is involved, it may be different from other kinds of phonemic processing involved in any other verbalisation contexts.

In this paper we report on the results of four patients suffering from a phonological reading impairment. Our results seem to confirm the possibility of the independent functioning of two kinds of phonological processing in graphemephoneme correspondence.

\section{Method}

Our aim was to test whether the two kinds of phonological processing (graphemic and phonemic) involved in tests were liable to function independently. In order to do this, two experimental variables corresponding to the theoretical variables were defined and two states for each were determined. Then a double dissociation (Teuber, 1955) in results of patients suffering from a phonological reading impairment was researched: some patients having a reading performance affected by the graphemic variable and not by the phonemic variable, and other patients having a reverse picture.
EXPERIMENTAL VARIABLES

\section{Graphemic processing}

The reading aloud of non-words whose graphemic composition was complex, was compared with the reading aloud of non-words whose graphemic composition was simple (their phonemic difficulty being equivalent). The reading of nonwords in which two letters corresponded to one sound (for instance, in French zou is pronounced $/ \mathrm{zu} /$ ) was assumed to be difficult; the reading of non-words in which each letter corresponded to a distinctly pronounced sound (EBU is pronounced /eby/) was assumed to be easy.

\section{Phonemic processing}

The reading aloud of non-words in which phonemic processing was assumed to be necessary, was compared with the reading aloud of non-words in which it was assumed to be less required (their graphemic difficulty being equivalent). The reading of non-words homophonic with a word (in French, the written non-word koK has the same sound / kok / as the word COQ) was compared with the reading of written non-words not homophonic with a word (FUJ pronounced /fy $z /$ does not correspond to the sound of a French word). In ( the first case, phonemic processing was assumed to be little required since the sound to be produced is the sound of a word. In the second case, the phonemic processing was assumed to be necessary since the sound to be produced is the sound of a non-word.

\section{TESTS}

The subject was asked to read aloud non-words composed of three or four letters. The non-words were selected so that it was possible to study independently the effect of each variable. Test 1 manipulated the graphemic variable, the phonemic difficulty being equivalent in both conditions. Test 2 manipulated the phonemic variable, the graphemic difficulty being equivalent in both conditions.

Test 1 (graphemic variable) was composed of 80 non-words divided into two lists. The 40 nonwords of list 1 had a written form compounded of three letters (vowel, consonant, vowel, for short VCV), each of them corresponding to a phoneme (for example, in French, IKo corresponds to the three phonemes, $i, k, o$ ). The 40 nonwords of list 2 had a written form compounded by three letters (CVV), it being necessary to process two of them together to form a single phoneme (for example, in French caU corresponds to the phonemes $k$ and $o$ ). The perceptual 
difficulty of non-words was equivalent in both lists, since the non-words were composed of an identical number of letters (3) and of similar kinds of letter $(2 \mathrm{~V}+1 \mathrm{C})$. The phonemic difficulty, as defined above, was also equivalent since, in each list, 20 of the non-words were homophonic with a French word, and 20 were not.

Test 2 (phonemic variable) was composed of 120 non-words divided into two lists. The 60 nonwords of list 3 were homophonic with a French word (in French, TIJ is pronounced /tiz/ just like the word TIGE), while the 60 non-words of list 4 were not (FUJ). In both lists, 40 of the non-words were composed of three letters (20 CVC and $20 \mathrm{VCV}$ ) and 20 non-words were composed of four letters $(20 \mathrm{CVCV})$. In every non-word, each letter corresponded to the sound of a phoneme. The written form of the non-word homophonic with a word was actually different from the written form of the word, so that it would have been very difficult to recognise the word perceptually (for example, the written form of the non-word кок is very different from the written form of the word coQ). In order to inform the subject of this possible reading strategy (reading aloud a non-word while thinking of the sound of a word), the experimenter told him: "this is not written as a word but its sound is just like the sound of a word."

Certain controls were carried out subsequently in order to make sure the results recorded were actually produced by the experimental variables and not by artefact.

Control on test 1 The sound forms of the nonwords in list 1 were composed of three sounds (eg iko) whereas the sound forms of the non-words in list 2 were composed of two sounds (eg, ko). This is the reason why the possible effect of the number of sounds to be evoked was studied. In order to do this, a list containing 40 non-words (list 5), composed of two letters corresponding to two sounds (CV), was added; the reading performance of each subject for that list was compared with the results for list 1 .

Controls on test 2 Two controls were carried out on test 2 , in order to makc sure that the subjects really evoked the sound form of a word and not the visual form of this word or merely non-words.

The purpose of the first control was to verify that the possible improvement in performance with non-words homophonic with a word was not the result of the evocation of the word's written form. If so, the more similar the written form of non-word and word, the better the non-words would be read, and vice versa. A visual proximity index (VPI) between the written non-word and the written word having the same sound was calculated (for example, ANÉ and ANNÉE). Then, the reading performance for non-words having a low VPI was compared with the reading performance for non-words having a high VPI. The visual proximity index was calculated by counting in the non-word the number of letters common to the written word (for example, among the five letters of the French word ANNÉE, three are found in the non-word ANÉ); this number was divided by the number of letters in the word (in the above example, VPI is $3 / 5$ or 0.60 ). The reading performance for 17 non-words with VPI $\geqslant 0.75$ was compared with the reading performance for 17 non-words with VPI $\leqslant 0.40$. All these non-words were drawn out of list 3 .

In the second control attempts were made to discover if the patients confronted with nonwords homophonic with a word (list 3 ) could actually evoke the sound form of a word and not only a meaningless cluster of phonemes-that is, if they had been able to adopt the strategy which was assumed to be efficient. If they had, they would produce words from list 3 more frequently than when they had to read, without instructions, non-words which did not have a word sound. In order to test this, the percentage of word-like misreadings in list 3 was compared with the percentage of word-like misreadings in list 4 .

\section{Subjects}

The subjects were patients with a cerebral lesion, suffering from a phonological reading impairment. The criteria used for their selection were as follows. 1. They misread meaningless stimuli whereas they read meaningful stimuli almost perfectly. This was established on the basis of a reading aloud test including 40 non-words (each composed of four or five letters) and 40 concrete and frequent nouns (each composed of five to 10 letters). 2 . They did badly on pointing out meaningless stimuli whereas they pointed out meaningful stimuli nearly perfectly. This was established on the basis of a designation test in which the patient had to point out from among 20 written stimuli the one corresponding to a stimulus pronounced by the experimenter; 40 non-words and 40 nouns were presented. 3 . Their oral language was considered to be normal or almost so, on the basis of the following criteria: spontaneous speech was fluent and informative and free from articulatory defect, phonemic or semantic paraphasia. syntactic defect, and anomia; repetition of syllables 
(10), non-words (10), words (10), and sentences (5) was correctly performed; object-naming was correct for 48 out of 50 pictures at least. 4. Their intellectual level was in the average range at least (above 25th percentile for the Progressive Matrices, 1938). 5. Their spans comprised at least four digits.

Ten patients were selected on the basis of these criteria. Of these ten subjects, the reading performances of four were sensitive to one of the two variables, those of two were sensitive to both variables, and those of the remaining four were sensitive to neither of the variables. Since the purpose of this study was to search for a double dissociation between results in two kinds of tests, only the results of four patients showing this are reported here. Tables 1 and 2 give the results for these four patients in the two reading selection tests.

\section{SUBJECT A}

This 47 year old right handed manual worker (JA) suffered a head injury in August 1974, with a left temporal contusion and unconsciousness for several hours. He visited the Centre du Langage of la Salpêtrière in March 1975, when he was suffering from severe amnesic aphasia, reading and writing disturbances, a calculation deficit, and slight finger agnosia. In September 1975, 13 months after the trauma, he fulfilled the selection requirements of this study, with minimal amnesic aphasia but with a severe reading impairment and a writing disturbance. The writing disturbance was especially characterised by errors which changed the sound of the word-

Table 1 First selection test: percentage of correct responses for reading aloud of 40 nouns and 40 non-words

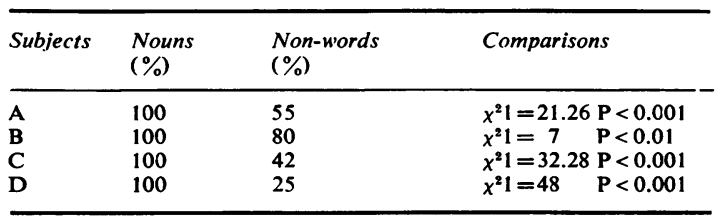

Table 2 Second selection test: percentage of correct responses for pointing out (upon spoken order) of 40 nouns and 40 non-words

\begin{tabular}{llll}
\hline Subjects & $\begin{array}{l}\text { Nouns } \\
(\%)\end{array}$ & $\begin{array}{l}\text { Non-words } \\
(\%)\end{array}$ & Comparisons \\
\hline A & 98 & 75 & $x^{2} 1=6.96 \mathrm{P}<0.01$ \\
B & 100 & 85 & $x^{2} 1=4.64 \mathrm{P}<0.05$ \\
C & 95 & 75 & $x^{2} 1=5.02 \mathrm{P}<0.05$ \\
D & 95 & 30 & $\chi^{2} 1=36.04 \mathrm{P}<0.001$ \\
\hline
\end{tabular}

for example, FENETRE was written FENATRE. Such errors were called "phonetic errors."

\section{SUBJECT B}

This 54 year old right handed chartered accountant (PH) collapsed in June 1975, after an angiogram to the right leg. He took the tests in September 1975, three months after the accident. He showed no sign of aphasia. He suffered from a disturbance of body image, constructional apraxia, and a calculation deficit. His reading and writing were impaired. Most of his writing errors were "phonetic errors."

\section{SUBJECT C}

In December 1973 this 37 year old right handed switchboard operator (MF) suddenly developed a right hemiplegia presumably caused by an embolus from her longstanding mitral valve disease. She suffered from severe aphasia with alexia and agraphia, minimal constructional apraxia, and a mild calculation deficit. In October 1975 , she fulfilled the selection criteria for this study. At this time, her reading was still severely impaired. Her writing was laboured with both phonetic errors and errors which were called "orthographic"-the written characteristics of $\triangle$ the word were changed but the sound of the wordg was not altered (for example, BATEAU was written BATO).

\section{SUBJECT D}

In March 1974 this 62 year old right handed company representative (RG) was operated on for a left parieto-occipital haematoma resulting from an angioma. After surgery, he suffered from right hemiplegia and aphasia, both of which regressed rapidly. He was examined in the Centre de Langage in May 1975, when the neurological signs were a right lower quadrantanopia, mild calculation deficit, slight constructional and corporeal apraxia, a naming defect for the various parts of the body, bilateral tactile aphasia (Beauvois et al., 1978), and severe alexia (Beauvois and Dérouesné, 1979). His writing disturbance was minimal, and was characterised by only orthographic errors. His speech and auditory comprehension were normal. He entered the study in October 1976, 31 months after the operation, when his symptoms were unchanged.

\section{Results}

The number of correct responses (non-words read without any mistake) was recorded for each list

.


and each subject. For each subject, the results for each of the two lists of a test were compared by a $\chi^{2}$ test (list 1 versus list 2 , list 3 versus list 4 ).

The results clearly showed a double dissociation (Tables 3 and 4). The performances of subjects $A$ and $B$ were affected significantly by graphemic difficulty and not by phonemic difficulty. Con-

Table 3 Test 1 (graphemic variable). Percentage of correct responses for reading aloud of 40 non-words in which each letter corresponds to one sound (list 1) and of 40 non-words in which two letters correspond to one sound (list 2)

\begin{tabular}{llll}
\hline Subjects & $\begin{array}{l}\text { List } 1(\text { IKO) } \\
(\%)\end{array}$ & $\begin{array}{l}\text { List } 2(C A U) \\
(\%)\end{array}$ & Comparisons \\
\hline A & 92 & 50 & $x^{2} 1=17.62 \mathrm{P}<0.001$ \\
B & 97 & 65 & $\chi^{2} 1=12.20 \mathrm{P}<0.001$ \\
C & 75 & 62 & $\chi^{2} 1=1.44 \mathrm{NS}$ \\
D & 65 & 55 & $\chi^{2} 1=0.82 \mathrm{NS}$ \\
\hline
\end{tabular}

Table 4 Test 2 (phonemic variable). Percentage of correct responses for reading of 60 non-words homophonic with a word (list 3) and 60 non-words not homophonic with a word (list 4)

\begin{tabular}{llll}
\hline Subjects & $\begin{array}{l}\text { List 3(TIJ) } \\
(\%)\end{array}$ & $\begin{array}{l}\text { List 4(FUJ) } \\
(\%)\end{array}$ & Comparisons \\
\hline A & 78 & 65 & $x^{2} 1=2.62 \quad$ NS \\
B & 96 & 98 & $\chi^{2} 1=0.008$ NS \\
C & 76 & 43 & $\chi^{2} 1=13.86 \quad$ P $<0.001$ \\
D & 78 & 36 & $\chi^{2} 1=21.28 \quad$ P $<0.001$ \\
\hline
\end{tabular}

versely, the performances of subjects $C$ and $D$ were affected significantly by phonemic difficulty and not by graphemic difficulty.

With the control on test 1 (table 5) there was no statistically significant difference in each subject's results between reading performance for nonwords composed of two sounds (list 1) and reading performance for non-words composed of three sounds (list 5).

In the control on test 2 there was no statistically significant difference between reading performance for non-words with VPI $\geqslant 0.75$ and reading performance for non-words with VPI $\leqslant 0.40$ (Table 6). Misreadings by subjects $A, C$, and $D$ in list 3 (homophonic non-words) were more frequently words (Table 7) than misreadings in list 4 (non-homophonic non-words). Subject B did not produce misreadings which were words.

\section{Discussion}

The present study concerns the phonological reading process. Its aim was to test whether it was possible to distinguish two kinds of phonological processing liable to function independently from each other in grapheme-phoneme correspondence. The graphemic processing was assumed to bring into play the rules peculiar to written language which would condition its translation into phonemes. The phonemic processing was assumed to bring into play rules peculiar to the production

Table 5 Control on test 1. Percentage of correct responses for reading of 40 three sound non-words (list 1) and for reading 40 two sound non-words (list 5)

\begin{tabular}{llll}
\hline Subjects & $\begin{array}{l}\text { List I (IKO) } \\
(\%)\end{array}$ & $\begin{array}{l}\text { List } 5(\text { KO) } \\
(\%)\end{array}$ & Comparisons \\
\hline A & 92 & 85 & $\chi^{2} 1=0.56 \mathrm{NS}$ \\
$\mathrm{B}$ & 97 & 87 & $\chi^{2} 1=1.70 \mathrm{NS}$ \\
$\mathrm{C}$ & 75 & 85 & $\chi^{2} 1=0.80 \mathrm{NS}$ \\
$\mathrm{D}$ & 65 & 70 & $\chi^{2} 1=0.20 \mathrm{NS}$ \\
\hline
\end{tabular}

Table 6 Control on test 2. Percentage of correct responses for reading of non-words homophonic with a word according to their visual proximity index (VPI) with this word

\begin{tabular}{llll}
\hline Subjects & $\begin{array}{l}17 \text { non-words with } \\
V P I \geqslant 0.75\end{array}$ & $\begin{array}{l}I 7 \text { non-words with } \\
V P I \leqslant 0.40 \\
(\%)\end{array}$ & $\begin{array}{l}\text { Comparisons } \\
(\%)\end{array}$ \\
\hline A & 93 & 64 & \\
B & 100 & 92 & $\chi^{2} 1=3.76 \mathrm{NS}$ \\
C & 87 & 76 & $\chi^{2} 1=0.04 \mathrm{NS}$ \\
D & 76 & 80 & $\chi^{2} 1=0.22 \mathrm{NS}$ \\
& & & $\chi^{2} 1=0.05 \mathrm{NS}$ \\
\hline
\end{tabular}

Table 7 Control on test 2. Percentage of errors which are words for reading aloud of 60 homophonic non-words (list 3) and 60 non-homophonic non-words (list 4)

\begin{tabular}{llll}
\hline Subjects & $\begin{array}{l}\text { List 3(TIJ) } \\
(\%)\end{array}$ & $\begin{array}{l}\text { List } 4(\text { FUJ }) \\
(\%)\end{array}$ & Comparisons \\
\hline A & 53 & 16 & $\chi^{2} 1=4.11 \mathrm{P}<0.05$ \\
$\mathrm{~B}$ & 0 & 0 & $\mathrm{NS}$ \\
$\mathrm{C}$ & 53 & 5 & $x^{2} 1=13.59 \mathrm{P}<0.001$ \\
$\mathrm{D}$ & 46 & 4 & $x^{2} 1=8.53 \mathrm{P}<0.001$ \\
\hline
\end{tabular}

of the sounds of phonemes from written language. In order to test this, two experimental variables corresponding to two kinds of processing were defined. A double dissociation was recorded in the results for four patients who had a phonological reading process disturbance after a cerebral lesion. Two subjects' reading defects were affected by graphemic difficulty and not by phonemic difficulty. The two other subjects showed the opposite picture-their reading defect was affected by phonemic difficulty and not by graphemic difficulty. These results strongly suggest the existence of two functionally independent kinds of phono- 
logical processing in the phonological reading process.

The analysis of experimental procedures used to make each variable easier, permits us to postulate some relationship between the phonological and lexical processes. Indeed, each experimental procedure can be thought of as an alternative strategy for patients suffering from an impairment of each phonological processing of reading. Two subjects suffering from a graphemic processing impairment read written non-words in which each letter corresponded to a phoneme (VCV) better than written non-words in which two letters corresponded to one phoneme (CVV). The first kind of non-words included two letters out of three whose corresponding phoneme has the same sound as their alphabetical name. These letters were vowels-for example, the phoneme corresponding to the letter $\mathrm{A}$ in AKO was /a/, like the sound of its French alphabetical name. In the second kind of nonwords, the phoneme corresponding to the letters never corresponded to their alphabetical names. In particular, most groups of two written vowels had no alphabetical names-for example, in French IN corresponds to the phoneme / $\tilde{\varepsilon} /$ which does not correspond to a letter name. If the subject could evoke the letter names, he was able to produce the first kind of non-words more easily than the second. Thus, it is possible that improvement of performance when non-words were graphemically easy, came from the use of an alternative strategy implying one stage of the lexical reading process. The subject would have adopted a letter naming strategy which was efficient for this kind of non-word. Letters would have been processed as visual images which were named by the subject, rather than as linguistic signs corresponding to a phoneme. The process used would have been lexical rather than phonological. This conclusion may be compared with findings recorded by Saffran and Marin (1977) in a patient suffering from a kind of alexia resembling phonological alexia. When he had to recognise words from homophonically written non-words, the closer the written form of non-words was to the written form of the word, the better the patient performed. This shows clearly that the use of a lexical strategy makes reading of meaningless stimuli possible in such patients. The fact that Saffran and Marin's results are different from ours (since the performances of our four subjects were not affected by visual proximity) does not alter this conclusion. It means only that there are probably several possible lexical strategies in the reading of meaningless stimuli.
Two subjects with an impairment of phonemic processing read a written non-word which was homophonic with a word better than when it was not homophonic with a word. The help given by this procedure did come from the sound form and not from the visual form. Reading performance was not related to the visual proximity between written non-words and written words of which they had the sound form. This means that the possible evocation of the sound form of a word was an alternative strategy to get over the impairment of phonemic processing necessary for the phonological reading process. Thus, there is another possible route between the phonological and the lexical process, which allows this alternative strategy.

One might wonder whether the two kinds of phonological processing implied in the phonological reading process are specific to reading. This would permit us to identify these two kinds of processing more effectively. Since this was not tested in the experiments reported here, the listing of normal and disturbed linguistic behaviour of the four patients can only lead to assumptions.

The speech of these patients was normal. Thiso is evidence that the phonemic processing involved in the phonological reading process does not take an active part in different modes of spoken language behaviour, especially in those which were studied-spontaneous speech, repetition, and naming. This phonemic processing must be distinguished clearly from other modes of phonemic processing involved in any speech behaviour. The latter are those which carry out phoneme selection and combination in the verbalisation of a word or a sentence, whatever the task is-spontaneous speech, reading, naming, repetition, etc. An example taken from pathological data may make it easier to understand the difference between these two kinds of phonemic processing. Some patients emit phonemic paraphasia whenever they have to speak, in reading aloud, spontaneous speech, repetition, naming. And some of them seem to be able to point out written non-words correctly upon spoken request which would prove that their implicit phonological reading was correct and thus, that they can carry out correctly the phonemic processing necessary to phonological reading. Thus, a dissociation between the phonemic processing involved in the phonological reading process and other phonemic stages in any speech behaviour may be observed.

These subjects' oral comprehension was less effectively tested than their oral expression, with the exception of that of a patient whose case has 
been reported upon elsewhere (Beauvois and Dérouesné, 1979). However, at a clinical level, the three other subjects' oral comprehension was normal. This underlines the fact that the phonemic processing involved in the phonological reading process is different from the phonemic processing involved in oral language understanding.

The four subjects' writing was impaired. And a particular kind of phonological reading impairment was found to be associated with a particular kind of writing impairment. The two patients with graphemic impairment made above all phcnetic mistakes (for example FENATRE for FENETRE) and few or no orthographic mistakes (for example BATO for BATEAU), whereas one subject with phonemic impairment (subject D) make orthographic mistakes but no phonetic mistakes (the second subject with phonemic impairment made both orthographic and phonetic mistakes). These results do not constitute any conclusive evidence. But the existence of two kinds of errors in these patients' writing raises the question of the possible existence of two kinds of agraphia related to two writing processes, in parallel with those which were distinguished in alexia (Marshall and Newcombe, 1973; Shallice and Warrington, 1975; Beauvois and Dérouesné, 1979). Lexical or orthographic agraphia would be characterised by the fact that writing can be carried out by phonological process (phoneme-grapheme correspondence) but not by lexical process. Such patients would be expected to write non-words perfectly but to write words phonetically, unable to give their orthographic characteristics. This might be the case with patient D. Phonological agraphia would be characterised by the fact that writing can be carried out by lexical and not by phonological process (phoneme-grapheme correspondence); such patients would be expected to write meaningful words correctly but to be unable to write nonwords.

Our results show that the reading impairment in the phonological reading process which is characterised by the fact that words are better read than non-words may result from either a disturbance of the graphemic or of the phonemic processing. The differentiation is based not on associated defects (aphasia or agraphia) nor on the site of the lesion, nor, at first sight, on alexia symptomatology (in the two kinds of alexia, the patients read words better than non-words). It is based on the identification of processing whose impairment produces the alexia. This differentiation is important because it may change the interpretation of studies on alexic patients. An example of this is the apparent contradiction between some of Patterson and Marcel's results (1977) and ours. These authors found that the reading performance of patients suffering from an impairment of phonological processing was not affected by the fact that a non-word was or was not homophonic with a word. This can be interpreted in two ways. Their patients may not have been suffering from a phonemic processing impairment, but from a graphemic processing impairment in which case it can be expected that homophony of a non-word with a word will not affect reading performance. Alternatively, their patients may have been suffering from a phonemic processing impairment, but were not given an efficient strategy, so that they processed all written non-word as meaningless stimuli, only using the disturbed phonemic process. Nevertheless, it must be emphasised that, clinically, this distinction will be observed only in exceptional cases. It is likely that many patients with a defect in phonological process are often suffering from impairment of the two kinds of phonological processing.

We thank J. K. Hylton from the Université de Paris XII for help in translation and $\mathrm{Dr} T$. Shallice for his helpful criticisms.

\section{Results}

Alajouanine, T., Lhermitte, F., and de Ribeaucourt, B. (1960). Les alexies agnosiques et aphasigues. In Les Grandes Activités du Lobe Occipital. Edited by T. Aeajouanine, pp. 235-265. Masson: Paris.

Andreewsky, E., and Séron, X. (1975). Implicit processing of grammatical rules in a classical case of agrammatism. Cortex, 11, 379-390.

Beauvois, M. F., and Dérouesné, J. (1979). Phonological alexia: three dissociations. Journal of Neurology, Neurosurgery, and Psychiatry, 42, 11151124.

Beau:ois, M. F., Saillant, B., Meininger, V., and Lhermitte, F. (1978). Bilateral tactile aphasia; a tacto-verbal dysfunctioning. Brain, 101, 381-401.

Benson, D. F. (1977). The third alexia. Archives of Neurology (Chicago), 34, 327-331.

Benson, D. F., Brown, J., and Tomlinson, E. B. (1971). Varieties of alexia. Word and letter blindness. Neurology (Minneapolis), 21, 951-957.

Dubois-Charlier, F. (1972). A propos de l'alexie pure. Langage, 25, 76-94.

Gardner, H., and Zurif, E. (1975). Bee but not be: oral reading of single words in aphasia and alexia. Neuropsychologia, 13, 181-190.

Kremin, H., and Dubois-Charlier, F. (1976). Les troubles de la lecture: l'alexie. Language, 44.

Marshall, J. C., and Newcombe, F. (1966). Syntactic and semantic errors in paralexia. Neuropsychologia, 4, 169-176. 
Marshall, J. C., and Newcombe, F. (1973). Patterns of paralexia: a psycholinguistic approach. Journal of Psycholinguistic Research, 2, 175-200.

Patterson, K. E., and Marcel, A. J. (1977). Aphasia, dyslexia and the phonological coding of written words. Quarterly Journal of Experimental Psychology, 29, 307-318.

Saffran, E. M., and Marin, O. S. M. (1977). Reading without phonology: evidence from aphasia. Quarterly Journal of Experimental Psychology, 29, 515-525.
Saffran, E. M., Schwartz, M. F., and Marin, O. S. M. (1976). Semantic mechanisms in paralexia. Brain and Language, 3, 255-265.

Shallice, T., and Warrington, E. K. (1975). Word recognition in a phonemic dyslexic patient. Quarterly Journal of Experimental Psychology, 27, 187-199.

Shallice, T., and Warrington, E. K. (1977). The possible role of selective attention in acquired dyslexia. Neuropsychologia, 15, 31-42.

Teuber, H. L. (1955). Physiological psychology. American Review of Psychology, 6, 267-296. 